\title{
Academic Cultures: Psychology of Education Perspective
}

\author{
Monica Mollo ${ }^{1}$ (iD
}

Received: 7 March 2021 / Revised: 17 June 2021 / Accepted: 19 June 2021

(c) The Author(s) 2021

\begin{abstract}
This work contributes to a wider range of research, the main objective of which is to investigate models of thought and behaviour that result from belonging to a given academic culture. The academic culture that will be examined is that within the university system, and this research will look at how this culture can take different forms. According to (Bourdieu, 1984), university professors hold an institutionalised form of cultural capital that places them in a dominant position within a field of power. The university system is immersed in a specific culture, and it expresses a given culture and understanding this culture will allow one to understand the system itself (Anolli, 2014). Cultural models are the result of a process of signification, which is understood as the ability of a group or community to elaborate a shared symbolic dimension around an object or symbol at a given historical moment. The cultural models that underlie the professional context orient social and organizational behaviour, which contributes to the construction, on a symbolic level, of identity.
\end{abstract}

Keywords Cultural capital $\cdot$ University system $\cdot$ Culture models $\cdot$ Professional context

\section{Introduction}

In this paper, we present and discuss the results of our study on the role of model cultures in a group of professors at the University of Salerno (Italy). The main objective of this research was to explore, from a socio-constructivist perspective (Vygotsky, 1978; Bruner, 1990; Cole, 1992; Vygotsky, 1978), thought patterns and behaviour resulting from belonging to a given university system with reference to the dimension of meaning. The explicit intent of this work was to identify the matrices of meaning (D'Andrade, 1995) and expressions of a

Monica Mollo

mmollo@unisa.it

1 Department of Human, Philosophical and Education Sciences, University of Salerno, Fisciano, Italy 
given academic culture that guide the activities of university professors. In our discussion of matrices of meaning, we make explicit reference to those that promote defined cultural models, ${ }^{1}$ shared representations of reality, and domain-specific knowledge devices (Cole, 1992) that motivate action in each situation and within specific contexts (Anolli, 2005; Gomes et al., 2018).

The disciplines of psychology, sociology, and anthropology have demonstrated the ways in which the thinking and social relationships that characterise professions are socially and culturally anchored. These have also been found to reflect certain aspects of social activities and the logic of the context in which these professions take place (Engeström, 1990; Jodelet et al., 1980; Kleinmann, 1975). Moreover, the role played by the sociocultural dimension in the construction of social identity has been widely documented by developmental psychologists (Gomes et al., 2018; Skinner et al., 2021; Valsiner, 1989; 1998; 2007). These studies have demonstrated how the sociocultural dimension contributes to the determination of work choices, the organisation of work, and, in a complementary way, to shaping the context in which professional activities take place (Gergen, 2001; Marsico, 2015).

\section{Theoretical Framework}

As a cultural organisation, the university system is simultaneously immersed in a culture and is an expression of a given culture (Savarese et al., 2013). Bourdieu (1984) stated that universities occupy a dominant role within a 'field of power' ${ }^{2}$. According to Bourdieu, it is possible to identify a dynamic of distribution of specific and symbolic cultural capital in the academic field. ${ }^{3}$ He held that this dynamic entails a game of interests, which involves specific actors, for the control of borders and 'newcomers'. In order to understand the mechanisms of domination and their reproduction (Bourdieu, 1984), it is necessary to adopt a sociocultural point of view that allows for the emergence and understanding of the symbolic tools of domination-such as knowledge, beliefs, motivations, and valueswhich underlie the procedures and practices adopted by university professors (Savarese et al., 2019).

The models that individuals build exist both inside and outside their own minds (Bateson, 1972; Shore, 1996); we cannot consider the elaboration of such models in terms that are exclusively internal or external to the individual. These models represent a socially distributed knowledge that exists between individuals and the context in which they operate, which is constructed based on the relationship the individual establishes between their own mind and their context; this relationship results from the use of artefacts in the individual's surroundings that guide their activity (Gomes et al., 2018; Iannaccone et al., 2018; Marsico, 2015, 2018; Savarese et al., 2013). This activity is not isolated; instead, it is intertwined with the activities of other individuals within institutions that regulate activities and relationships. Knowledge, therefore,

\footnotetext{
1 A cultural model corresponds to schemes or maps of representations of reality (D'Andrade, 1995; Anolli, 2005).

2 According to Bourdieu (1984), the structure of the university field reproduces the same structure as the power field by acting in terms of selection and inculcation.

3 Bourdieu's (1984) concept of capital indicates that these resources (economic, social, symbolic, and cultural) are acquired in different ways, the value of which changes according to the situation; relationships and spaces are built around capital.
} 
is contextualised as the result of meanings produced by individuals and their ability to share these meanings, beliefs, values and activities (Gomes et al., 2018; Marsico et al., 2015).

Cultural models are the result of a process of signification, which is understood as the ability of a group or community to elaborate a shared symbolic dimension around an object or symbol at a given historical moment (Marsico, 2015, 2018; Savarese et al., 2013). This does not mean, however, that individuals who carry out the same activity within the same context will share the same system of knowledge and beliefs - in fact, the variety that exists in the social context and among its members does not allow cultural models to be reduced to the mere sharing of meanings, since 'each individual is representative of different subcultures' (Anolli, 2005, p. 148). Consequently, it seems right to refer to cultural models rather than reducing them down to one model, because individuals' construction and interpretation of reality is linked to their adopting a particular point of view (Mellone et al., 2020). Therefore, on a theoretical level, the construction of the professional role must be significantly influenced by personal biography, professional experience, and the individual's cultural context. The cultural models that underlie the professional context orient social and organisational behaviour, which contributes to the construction, on a symbolic level, of identity (Marsico, 2015, 2018; Savarese et al., 2013). On the methodological level, then, it appears that an explicit reference to the narrative and culturalist dimensions is essential (Bruner, 1990, 1992, 1994, 1996; Marsico, 2015, 2018; Vygotsky, 1978; Wenger, 1998)ifindividuals are to organise, attribute meaning, and communicate or to divide their experience and interpretation of reality (Gomes et al., 2018; Savarese et al., 2019).

The purpose of the current research is to investigate the meanings, values, and practices inherent to academic culture and to analyse the thought and behaviour patterns of a group of university professors. In particular, we aim to highlight the collective framework of meaning and social representations that allow us to correctly understand the relationship that professors establish with the knowledge that underpins and guides their teaching and research activities, as well as to dismantle the theories of common sense that are often held with regard to the role of university professors. In this work, we conceptualise culture in psychosocial terms as a local and situated psychological construct-the result of shared representations of the university context (Gomes et al., 2018; Salvatore, 2005), which includes the concept of culture as a system of rules and local meanings. Our investigation of cultural models facilitates an explanation of the levels of conformity to the culture of belonging and the differences found within the same culture; it will also provide insight into how such models, once internalised, evolve over time to contribute to the construction of new cultural models (Gomes et al., 2018; Marsico, 2015, 2018).

\section{Purpose of this Research}

This study's overarching purpose was to investigate and understand the cultural models that underlie the profession of university teaching. In this research, we conceptualise culture in psychosocial terms, as a psychological construct with a local and situated character that is the result of shared emotional symbolisations ${ }^{4}$ of the university context.

\footnotetext{
${ }^{4}$ Categories are understood as intersubjective processes of affective rather than operational categorizations of reality (Salvatore, 2005).
} 
Our specific research objectives were to.

1. Verify the presence or absence of local cultural models

2. Analyse the main characteristics of such models

3. Explore the nature of the differences between models

In addition, we also explored how cultural models guide professors' activity, the development, and definition of professional identity.

\section{Participants}

Twenty-one professors from the University of Salerno took part in the research: 10 from the humanities and 11 from scientific disciplines. The participants had lengths of service that ranged between 10 and 30 years. We used a random method to identify the study's participants; we contacted professors via email through an invitation letter in which we explained the research and its purpose. The invitation was sent to 50 professors $(25$ science professors and 25 humanities professors); 21 of those contacted responded to the invitation.

\section{Methodology}

This research is inspired by the professional biography construct, which is part of the broadest tradition of narrative psychology (Bruner, 1990, 2010). Data were collected using a semi-structured narrative interview (Bruner, 1992, 1994), and we recorded and transcribed all of the interviews. The semi-structured interview was divided into two parts and consisted of a total of 11 questions. We used a qualitative approach to analyse the data, and the content analysis (CCA) (Berelson, 1954; Blanchet, 1985), we performed aimed to identify local cultural models in accordance with the conclusions of two independent judges.

\section{Interview Structure}

The first part of the interview (questions 1 through 7) contained open-ended questions that invited the faculty member to 'tell' their profession-i.e. narration of the professional story. The objective of this part was to bring out the participant's vision of their role and the university context. This part of the interview was, in turn, divided into three dimensions:

(A) Dimension I: Identify the main characteristics of the university context and the professor's role (past and present), as well as the emotional significance that role, the context, and the students have for the professor.

(B) Dimension II: Identify the participant's moment of identification with their professional role (i.e. when they felt like a professor).

(C) Dimension III: Identify the participant's future representation of the university and their role. 
The second part of the interview (questions 8 through 11) examined the participants' degree of satisfaction (Salvatore, 2005), which we measured using a scale from 1 to 10 . The scale investigated the professors' professional lives (present, past, and future) within a temporal space of 5 years. We also investigated the degree of the professors' emotional involvement with the profession, again using a scale of 1 to 10 .

\section{Data Analysis}

The analysis was based on the interpretation of the professors' responses. The interviews were transcribed and protocoled. ${ }^{5}$ The content analysis (CA), in particular, allowed us to identify general categories in the interview protocols. We carried out the data analysis discussed below through a thematic categorisation of the transcribed texts, which required a CA (Berelson, 1954; Blanchet, 1985) in accordance with two independent judges. ${ }^{6}$ In this phase, we were required to respect some rules of classification: (1) the uniqueness of the classification criterion, (2) the mutual exclusivity of the categories, and (3) the exhaustiveness of the set of categories. Two types of categories emerged from this initial exploratory analysis: thematic categories ${ }^{7}$ and semantic categories. ${ }^{8}$ This study's particular focus was on the semantic categories that emerged. Further to this, we analysed the frequencies of the categories that emerged, and at a later stage, we performed a correspondence analysis. ${ }^{9}$ Through the correspondence analysis, ${ }^{10}$ we were able to identify the professors' placements in relation to the variables identified by the CA. This analysis made it possible to define a map that grouped the professors in relation to the main active variables.

We divided the categories into main themes (MT) and secondary themes (ST). Some examples taken from the transcripts that refer to the MT and ST that emerged from the analysis are presented below.

\section{Results}

In this section, we will describe the cultural models we identified through an interpretation of the autobiographical narratives operated by the judges. Defining cultural models has proven to be very complex due to the multiplicity of interpretative levels that emerged from

\footnotetext{
5 The data in their entirety are available to researchers who may be interested. The interview protocols are in Italian.

6 Two researchers independently conducted the analysis of the text by segmenting it into main and specific themes. They then compared the results; in the case of discrepancies, they compared the analyses and, if necessary, redefined the themes until they reached a satisfactory degree of agreement.

7 Classified as units of analysis that relate to the same theme or topic.

8 Classified as units of analysis that assume, in the context unit, the same or similar meanings.

9 The variables we considered included discipline (scientific and humanities), role (associate and full professor), and categories that emerged from the content analysis. We used T-LAB software to perform the correspondence analysis.

${ }^{10}$ Not all of the categories that emerged from the content analysis are present in the correspondence analysis, because it was based on particular statistical and mathematical principles. The values that have a 'weight' within the analysis are shown (Lancia, 2004). Given the small number of participants (21), some of the categories that emerged were so infrequent as to not be significant. Given the qualitative nature and purpose of the research, the correspondences analysis was performed only to clarify the professors' placements with respect to the categories in order to define the cultural models.
} 
reading the interview transcripts. For this reason, we carried out multiple analyses ${ }^{11}$ on the corpus of data, which provided the judges with useful elements from which to reconstruct cultural models.

Four cultural models emerged from the transcript analysis (Bruner \& Feldman, 1999). These models should not be considered to have rigid boundaries, however; in fact, similar and dissimilar aspects can be identified, including elements of sharing such as knowledge, practices, and beliefs that differ in their functioning in relation to the environment and social influence. Our analysis of the transcriptions revealed four main themes (MT1, MT2, MT3, and MT4), as well as a number of specific themes (ST).

The MT and ST were used to reconstruct four cultural models. These cultural models (CM) and some examples of the ST are presented below.

\section{MT1 (Model 1): Shared Social Construction ${ }^{12}$}

This research was aimed at understanding the patterns of thought and behaviour that guide activity. Therefore, it was necessary to identify, from the point of view of the participants, elements that were particularly significant for the data interpretation. Therefore, we focused our analysis on representations of the profession that involved the beginning of the participants' professional history as well as their current situation. The initial part of the study identified the professors' early impressions of the university and of their roles, and moreover, the presence of what the judges defined as 'meeting'. This theme refers to the emergence, from the interview protocols, of the figure of a mentor or professor who directed the participant towards a university career by choosing them as a collaborator. We also identified the nature of the relationship (i.e. the main characteristics). Using the narratives to identify the presence —or the absence — of a mentor and of the type of professional relationship allowed us to hypothesise that, in some cases, the emergence of a local academic culture can be attributed to the cultural influence of mentors on students. During the second part of the study, we identified the current representation of the university and the role and actions carried out by the lecturers in professional practice. Furthermore, we compared the participants' initial representations with their current ones, which made it possible for us to identify changes in academic culture where they were present.

Some $^{13}$ of the ST present in MT1 are presented below:

- ST3: Meeting the mentor, as the foundation of cultural and scientific competence

- ST5: The university as an ideological space through which teaching and research converge

- ST6: The role of teaching as a cultural and educational model

- ST7: Identification with one's role with regard to one's relationship with students

\footnotetext{
11 Content analysis; frequency analysis; correspondence analysis; lexical analysis (emotional connotation, narrative linearity and autobiographical position). Given the objectives of this paper lexical analysis, frequency analysis, and correspondence analysis will not be presented.

12 Categories related to the professional role emerge from the analysis of autobiographical narratives: building a culture, sharing beliefs, and in creating projects with students and colleagues. Additional categories that emerge from the analysis of the professional role (present, past, future) are a sense of community (community composed of students and faculty) and the sharing of social and cultural meanings.

13 Twenty-nine specific themes were identified, but for space reasons, we will only present a few examples.
} 
The first of the CM that emerged from the biographical reports places the university at the foundation of relational, social, and communicative practices: the university, for these professors, takes the form of a social construct. This model refers to representational aspects of the profession and the university; for example, a prominent role is played by the teaching of and relationship with students. The analysis of the autobiographical reports showed that the construction of this cultural model is linked to meeting the mentor. The nature of this meeting - particularly when it is described in terms of cultural fellowshipcan affect, from the beginning of one's university career, the concept of professional activity in terms of building knowledge as a collective process shared between the professor and the student.

\section{Example 1: Associate Professor, Humanities, M}

Interviewer: Was there a person who influenced your professional choice?

Professor: Certainly yes certainly yes . . . in the sense that I want to say on the one hand how to say it is a cultural situation in the sense that I told you before that the university represented . . . had this halo of attraction . . . on the other hand I came across a person who has been a constant point of reference in my training as a psychologist [. . .] with whom we then built a partnership compared to many activities a ... intellectual partnership strong enough ... I mean very constructive experiences.

For professors who relate to this model, the idea of teaching as a shared construction of knowledge remains stable over the years. ${ }^{14}$ Further to this, scientific research is an indispensable tool for improving the teaching, and therefore the training, of students. These professors began reconstructing their professional history by narrating their professional experiences at the beginning of their careers and their relationships with their mentor and their students, for example: '[...] the choice ${ }^{15}$ depended, as it always happens, on the people you meet along... along your career, at the beginning as a student and then afterwards in the following developments and... in practice... the desire, the idea of dedicating yourself to the university activity is born a little bit because maybe you meet a person with whom you fall in love from the scientific point of view, maybe for the didactic abilities for a whole series... situations [...]'. The discovery of one's professional identity seems to occur in a completely random way, described by the professors as a slow process that leads to recognition of their role through their students and/or collaborators and/or colleagues, for example ' $[\ldots]$ but... I think that this... that there is not a moment is a continuous phase ${ }^{16}[\ldots]$ '. This recognition does not appear to be exclusively linked to their institutional role, as the

\footnotetext{
14 Such elements are always present in narratives. The questions aimed to investigate the representation of the past profession (example: what were your goals when you started? Tell me your story from the beginning...), present (example: Today, what are the goals and objectives of your profession? Have the goals and objectives of your profession changed since the past?) and in the future perspective (what do you think the profession will be like in the next 5 years? will your role change? will your goals change? If you were to make predictions, what path do you think this profession will take in the next five years?).

15 This answer was given when the interviewer asked him: "First of all I would like you to tell me about your profession from the beginning (this is the first question).

16 Sample answer to the question: Was there a time when you identified with your profession? Where did you feel like a college professor?
} 
participants who referred to this cultural model had a clear vision of the university and of the function of a professor. To them, the university is a place through which research and teaching converge.

\section{Example 2: Full Professor, Humanities, M}

Interviewer: What are the objectives of your profession today?

Professor: My aim is to bring to teaching a part of the research without which it would not be possible . . to teach with enthusiasm and then establish a good relationship with the students that communicates beyond the specific contents the various courses that one prepares curiosity, the surprise of understanding . . . these are lessons that go beyond the subject of the course.

\section{Example 3: Associate Professor, Sciences, M}

Interviewer: There was a moment in your profession when you identified yourself, a moment when you said I am a university professor, now I feel like a university professor?

Professor: A particular moment no the competition no in fact a particular moment no there are several moments then the moment in which you feel university professor are the moments in which you feel the appreciation of the students after a lesson for example of the times you are particularly satisfied with the lesson and you feel alive the appreciation of the students there you feel university professor because you feel a point of reference for the students and another when one can feel like a university professor and ... when one reaches a prestigious scientific result such as the publication of an article in an important journal or the presentation of a successful presentation in a conference of a certain importance . . . in short, these are the two typical situations in which one feels like a university professor and perhaps one feels like saying that the status of professor is linked more to the appreciation of the students.

It is clear from these excerpts that one of the main tasks of the university professor, in the context of this model, should be to combine teaching and research as a reference point of training and a model for students.

\section{Example 4: Full Professor, Humanities, F}

Interviewer: If you were to make predictions about what path you think you will take in your profession over the next five years?

Professor: In the next five years . . for three more years I will be engaged as dean of faculty, then I repeat afterwards . . . as I said before at the beginning I will return to the study, to research, to teaching and what we still have left in short.

The future goals for this participant translate into the hope of being able to dedicate themself again - towards the end of their career and after having fulfilled all their duties, including institutional positions - to teaching and research. 


\section{MT2 (Model 2): The Culture of Development ${ }^{17}$}

We characterised the second cultural model in terms of space for research and scientific production at the university in order to produce knowledge useful for research (as the first priority) and teaching. Research, and the scientific production that comes from it, can be seen as an engine of scientific and cultural development that represents the main function of the university, as well as the main activity of the university professor. This model is associated with those professors who, from the beginning of their professional careers, had a clear idea of the path they intended to follow. For these professors, the cultural model emerged before the beginning of their careers and consolidated once they met their mentors who-as with the professors who belonged to the previous model—represented a memory accompanied by a strong emotional charge. For these professors, the mentor represented a scientific model to imitate and pass on to new generations, as well being the one who consolidated a particular scientific and academic culture.

\section{Example 5: Full Professor, Humanities, M}

Interviewer: What are the objectives of your profession today?

Professor: I believe that we teach how to become a professor by imitating the models that have been most profitable for us . . . in short . . . those we have trusted the most İ the good professors at bottom.

Professors who relate to this cultural model regard professional status in terms of the external dimension ${ }^{18}$ : recognition of the scientific and academic world.

\section{Example 6: Full Professor, Sciences, M}

Interviewer: There was a moment in your profession when you identified yourself, a moment when you said I am a university professor, now I feel like a university professor.

Professor: Yes and . . clearly it is a path that ... is followed and then ... you grow a little bit every day . . . but you realize that you are a university professor . . . when people expect you to be able to give answers on ... certain issues and then evidently believe ... that you are ... able to give those answers ... well certainly is very nice in short.

\footnotetext{
17 The term 'developmental culture' is deliberately inspired by — and given some common elements of Bergquist's (1992) third type of academic culture: 'The Developmental Culture'. For further information, see Bergquist (1992). The Four Cultures of the Academy: Insights and Strategies for Improving Leadership in Collegiate Organizations. Jossey-Bass Publishers.

${ }^{18}$ One of the last aspects concerning this moment in the profession relates to the dimension of attribution, which emerged from question 'Was there a time when you identified with your profession? Where did you feel like a college professor? Professors were asked to identify, if possible, the moment when they perceived themselves as university professors'. Two dimensions were identified by the analysis: internal and external. The internal dimension refers to those professors who, in the interviews, declared that they felt they were professors because of their qualities or because of their vocation for this work; on the other hand, the external dimension is typical of those professors who declared that they felt they were professors because of the recognition they received from students or from the academic world.
} 


\section{Example 7: Full Professor, Sciences, M}

Interviewer: When you started this profession what were your goals?

Professor: at the beginning it wasn't very clear I think that basically when one starts as a boy the thing that one sees in the university is more directly the research activity, on the question of teaching and all the possible obligations of a university professor... the idea wasn't very clear so basically... the beginning was the passion for research this was what guided me. Initially the goal was only how to say... I liked to study... I liked to do research... I liked to face this scientific discipline and eventually find the solutions, so the goal was well defined, then slowly, slowly, obviously... once one is inside the university system, one begins to understand that there are other issues and those, in fact, let's say... how to say... we faced them as they came (...)

Professors who relate to this model are focused on themselves and their professional achievement at the beginning of their careers. In their narratives, these participants described themselves through the activities they had carried out and the awards they received; overall, they were oriented towards research and scientific production.

\section{Example 8: Full Professor, Sciences, M}

Interviewer: Have the objectives that led you to choose this job changed over the years, since the beginning?

Professor: The objectives have actually changed a little bit in the sense that as long as you are young you think exclusively ... a least in the scientific faculties ... you think exclusively to devote yourself to research activities so initially the objectives are those of . . . let's say to produce as much as possible from the scientific point of view publish in international journals accredited so you devote yourself almost exclusively to research activities with a few distractions of other ... of other kind as ... as you go on obviously changing the role also change the needs change.

For some of these professors, scientific production and research are considered a privileged means for the acquisition of respect and power within the academic world.

\section{Example 9: Full Professor, Sciences, F}

Interviewer: What are the aims and objectives of your profession today?

Professor: Let's say that the main objective is that of scientific production . . . the university is divided into two main areas: teaching and research . . . research allows you to obtain funding . . . also important . . . to make the university known . . . brings prestige.

Unlike the professors who relate to the previous cultural model, the professional role of those in this group is in transition. Their role has been transformed and decentralised and there has been an attention shift from the individual ('me') to the other ('collaborators'). For these professors, the objective is to carry forward the interests of the group, even if this entails the burden of taking on institutional positions. 


\section{Example 10: Full Professor, Sciences, M}

Interviewer: Have the objectives and aims that led you to choose this job changed over the years compared to the past?

Professor: You go on ... obviously changing the role also change the needs . . . because as we say you become bearers not only of strictly personal interests but more than anything else of the interests of a group . . . because you create a team and meanwhile you can do many things if you have valid collaborators . . . and obviously the more collaborators you have the more you can produce from the scientific point of view the type of activity changes because you no longer do so much research in first person but more than anything else you coordinate it . . you give the addresses the suggestions but let's say ... you are no longer in a certain sense . . . a research operator so it is difficult to do computer processing or laboratory tests in the first person ... you give only the indications on how to do it ... on how to do things ... the needs change because one creates a group ... a team has to take charge of the future prospects of the people it is following.

Teaching provides a way to build qualified knowledge through the incorporation of research. For this reason, it is important that the group (i.e. the collaborators) represents the professor's identity and offers the possibility of developing and handing down a form of scientific and cultural heritage (Bordieu, 1984). Professors who relate to this model are trained in research and remain linked to it throughout their professional careers; in this case, the soul of a researcher coexists with that of a professor. One thing that remains stable for those in this group is that even if they give a different outward appearance for the good of the group, they remain, at their cores, researchers.

\section{MT3 (Model 3): Transmission of Cultural and Scientific Knowledge}

The third cultural model takes the form of knowledge transmission. The function assigned to the university and to its professors is to transmit knowledge, practices, and scientific skills to students and collaborators. In this cultural model, traits from the first model (i.e. shared social construction) and the second model (i.e. the culture of development) converge. In the first model, the focus of the professors was on building knowledge and their relationships with students, while in the second model, research and the working group were the main focus. This model represents a mediation between research/group and didactics/students, with these elements merged to become a single element. While teaching and research are considered to be the central elements at the base of professorships and the university from the beginning of one's career, this cultural model leads those who relate to it back to the nature of the scientific and cultural relationship.

\section{Example 11: Full Professor, Humanities, M}

Interviewer: Compared to when you started, when you started this profession, have your goals changed?

Professor: No [. . . I think that each one of us can give . . . at least that he is not a scientist much more dedicated to teaching than he can give only to research so ... I think that the function of the university professor has been and is high education 
and research ... not research and ... in his spare time high education just to make it clear.

\section{Example 12: Associate Professor, Sciences, M}

Interviewer: What are the aims and objectives of your profession today?

Professor: Then I am uncertain ... there are two objectives that go hand in hand and are one in the field of research and one in the field of didactics . . I have to say with a lot ... with ... a lot ... how to say ... passion to try to place the research that we do within a European and international context [. . . ] this essentially means making contacts and collaborations with groups ... with groups of considerable capacity that are in Italy in Europe abroad and this is definitely one of the objectives . . . from the didactics point of view . . . I think I put a lot of effort in my didactics [. . . it's a relationship that I like very much . . . that is to say I have fun doing lessons and I enjoy that students learn in a funny way ... I am considered one of the toughest professors I take very difficult exams I am very demanding of people but in general . . . I have a very good relationship with people I mean with the students . . . and I like this very much . . . I would like the structure that welcomes me ... I mean . . . to have the same goals that I have . . . in general didactics is not always at the first place within the Italian university and we are no exception.

These reports demonstrate that professors who relate to this model tend to oscillateboth in their current professional phase and in their perspectives on the future-between the individual and the collective dimensions of the profession. The individual dimension in particular seems to be linked to the importance that professors attribute to research and scientific production. For some of these professors, their identification with their role involves recognising their skills as individuals, while on the other hand, the collective dimension is linked to the sphere of their relationships with students and collaborators. In fact, for professors in this group, recognition of their role is not internal; it comes, instead, from their relationships with their students and the actions they take with regard to them. In many cases, those in this group will take on the interests of their collaborators by trying to adapt to the situations that the university offers, even if this involves taking on institutional positions.

\section{Example 13: Full Professor, Sciences, $M$}

Interviewer: If you were to make predictions, what path do you think the profession will take in the next 5 years?

Professor: But if it were exclusively up to me ... I would continue to do exclusively research activities ... let's say, however, why that research activity and to do it well in order to increase the sectors of interest ... not only to deal with certain themes, therefore to expand research activities from ... from the point of view of . . . of the topics dealt with obviously there is the need I was saying before to carry on a team then let's say . . . to carry on a team it could be positive also to occupy an institutional role even if unfortunately I don't have the character and maybe also the aptitudes for this career that I would define more of university politics than of . . that is not research, let's say but if necessary I am suitable to do a little bit of everything in life you learn to do a lot of things. 


\section{Example 14: Associate Professor, Humanities, M}

Interviewer: What are the objectives of her profession?

Professor: To grow and improve more and more this surely and above all to make grow the people who work with me.

As professors, these participants assume the responsibility of being a pivot in the formation of their collaborators and students. They view research as a useful tool for the improvement of their teaching, and they hope to have the opportunity in the future to return to their origins as researchers. Therefore, this cultural model is characterised by the convergence of teaching and research and one's relationship with students and collaborators. For those in this group, the transmission of knowledge has two main meanings: the first consists of the transmission of dynamic knowledge, which has been enriched and kept updated through research, to one's students; the second is group-oriented and involves the transmission of scientific and cultural skills.

\section{MT4 (Model 4): Training and Research System}

This cultural model symbolises the university in terms of an education and research system. While the professors who related to this model maintained their recognition of the importance of research, their focus was on the pleasure of teaching and training students. In fact, the professors who related to this model were divided between those who identified themselves through their professional role-especially when their work was recognised by the academic world - and those who perceived themselves as professors through their relationships with students. What emerged in the reports is that this identification sometimes takes place when a professor perceives that their actions towards their students have had an effect and that they have contributed to the quality of their student's training.

\section{Example 15: Associate Professor, Humanities, M}

Interviewer: Was there a moment when you identified with your profession?

Professor: When you have a long time in this job . . . well there are moments when you feel you have done a good job more than other moments . . it's when after a long time you find someone ... a student . . . you meet someone who tells you ... ah how much I needed those things and those experiences I had with her . . . this is one of the moments when you touch with concreteness that maybe you have reached that combination of teaching and research ... presence and witness of you in a place... which is our work.

\section{Example 16: Associate Professor, Sciences, M}

Professor: A change maybe happened when . . . the close interaction with students began [. . . ] when I started to follow students with thesis in which there is a much more direct relationship ... then it is to see in some respects the replica of what happened to me when I was a student [. . . ] it is extremely gratifying [. . . it was just a point of . . . in short ... how to say ... to see the enthusiasm that I had felt [. . . replicated in the others that was very nice ... that was a very pleasant thing . . . actually 
there was the passage from researcher to professor ... and let's say that ... that's a very nice thing.

\section{Example 17: Full Professor, Sciences, $F$}

Professor: On March 1st of this year I took up service as an ordinary . . . this could be an answer but ... instead no ... let's say maybe the best moments are those in which you feel affirmed with what you do . . . so I don't know when maybe when you have contacts with foreign professors who recognize your work ... things of this kind ... that however are the most stimulating because you are confronted with different realities.

These professors seem to remain immersed in a transitional phase, to be in the midst of moving from an initial role that focused on research and personal affirmation (i.e. the individual dimension) to a new role that is centred on teaching (i.e. an element, linked to research, that was present at the beginning of their career in a minimal way) and on the training of students (i.e. the collective dimension). For those in this group, research continues to carry weight in their professional lives, as does scientific collaboration with other colleagues, but neither of these is regarded as scientific power or cultural heritage.

\section{Conclusion}

The goal of this research was to demonstrate the existence of local CM that are inherited, built up, defined, and developed over the years and to show that these models not only orient the activities of professors, but they also represent the ways in which professors interpret and give meaning to their surroundings. As mentioned above, CM are shared representations that are linked to the subjects' lived experiences; these experiences, however similar they may be, can never be exactly the same. For this reason, it is possible to detect differences within the models. Furthermore, several different models may coexist in one individual's experience. Two dimensions emerged from our analysis of the autobiographical reports - an individual dimension and a collective dimension-within which the previously discussed CM are defined and organised. In accordance with Bruner (2010), these two dimensions rest at the heart of professors' professional activities and the way they live the university context; in fact, the author goes so far as to state that 'our way of understanding the world and responding to it in an appropriate way constitutes, at the same time, the expression of our individuality and our participation in the wider context in which we live' (p. 9).

The individual dimension refers to the salient components of professional activity: research and scientific production. These components, on closer inspection, represent the expression of individuality that is linked to the role of researcher. However, depending on the cultural model in which they are used, research and scientific production take on different roles and meaning; they can be considered in terms of political power, prestige (Bourdieu, 1984) or as essential elements of teaching and innovation. Nevertheless, regardless of their use, these elements represent the most intimate (understanding in emotional terms) and stable (elements always mentioned in the narrative). Research assumes a relevant role; from the professors' narratives, two parallel developments concerning the role emerge: personal and institutional. The professors, in their future perspective, include changes in the role (understood in terms 
of organizational and institutional changes), but they declare their intention of maintaining a personal professional trajectory by orienting their activity toward research (a return to the origins). The research represents the strategy for managing the (feared but inevitable) institutional changes in the role. Safeguarding this individual dimension represented by research would seem to be the modality adopted by professors to cope with the sense of uncertainty about the future. The professors anchor themselves to this element (constant presence from the beginning to the end of the narrative) continuing in this way (beyond the changes) to maintain a stable and unchanging part of their activity, for example: 'In the next 5 years for three more years I will be busy as dean of faculty then after I repeat as I said before at the beginning, I will return to study... to research'.

The collective dimension is articulated within the sphere of relationships, which is, in turn, composed of certain essential elements, including the individual's relationship with their professor, relationship with collaborators, and relationship with their students. The data gathered through this research also highlighted the fact that within each relationship, there is a field of action within which these relationships are realised and acquire meaning. Further to this, the definition of this field of action is linked to the cultural model to which the professors relate. While the collective dimension represents the dynamic and fluid aspect of the role and the CM, relationships represent the core of a professor's identity scheme.

Unlike research, relationships represent a stable element (albeit with different implications) of professional activity. Relationships change from the beginning to the end of a career, and as their relationships change, professors' activities also change. The first important element that emerged from the narrative was the participants' encounters with a mentor whose guidance formed the foundation for the construction of a particular cultural model. In some cases, this mentor also represented the motivation behind the professors' choices with regard to which cultural model to imitate. The CM mentioned above reveal how the mentors' own initial training contributes to the construction of their own cultural model by directing them towards particular professional paths. For example, professors who experienced this relationship in terms of an intellectual fellowship were also those who remained with their mentor and continued, albeit with some modifications, the cultural model they learned. On the other hand, however, professors whose relationship with their mentor took the form of an apprenticeship tended to modify the cultural model, primarily by enriching it with other elements that became important to them through their professional activities. The second aspect of the collective dimension relates to the professors' relationships with employees, particularly in terms of training. For some professors, this relationship plays a fundamental role within the university context, and the meaning given to this relationship depends on the cultural model to which the professor relates. For the group that considered the training of students to be a valid endeavour and for whom teaching represented a way to hand down their scientific and cultural heritage, the professors had the opportunity to keep their cultural model alive (a role that some of them would have filled for their own professors) despite the difficulties and changes that can affect the academic world, it is inherited system (and to be handed down to new generations) of mechanisms of domination and control of the university context (Bourdieu, 1984). This legacy presents a kind of moral testament left by professors to future generations of researchers; this allows them, once their teaching career is over, to return to the individual dimension of researcher. They have the opportunity to do this because the professor role will have been assumed by another who will not only carry the legacy forward but will develop and improve it in their own ways.

Finally, didactics and research were found to be among the most important elements of university professors' activities. Didactics refers to the method through which professors 
bring together the individual and collective aspects of different CM They represent the key elements necessary for a quality professional action. In this case, the aim of this action is to improve the training of students, and it is thanks to the students that professors can achieve this union of the individual and the collective, for example: 'goals and objectives... then... the purposes of the university are of a twofold nature, there are purposes related to the teaching activity, other purposes related to the scientific activity... as far as the scientific activity is concerned... there is a hedonistic aspect as far as the teaching is concerned... the purpose perhaps... the greatest satisfaction of a professor is to enthuse the students to feel that the students are passionate about the discipline'. In each of the different models, a focus on the students is always present; for some professors, they represent the future, while for others, the students are the ones who may one day take on the role of university professors themselves. This observation emerged from the interviews, where it became obvious that the individuals who the professors saw as collaborators were former students that were distinguished for their skills. Therefore, it is important that professors are provided with quality training in a cultural, scientific, and educational model that they can follow.

Moreover, according to the professors who participated in this research, this can only happen through the convergence of teaching and research. It can be deduced, then, that professors elaborate and build CM through both personal (i.e. motivation to choose) and professional biographical elements (i.e. experiences related to research, presentations and publications) and the relationships they weave in the context of their profession.

In summary, the two dimensions that make up these CM characterise professors' roles and professional activities of professors through the individual dimension, which represents stable and unchangeable aspects such as research and scientific production, and through the collective dimension, which represents the dynamic and fluid aspects of the work and finds its raison d'être in the significant others (i.e. mentors, collaborators and students) and the different modes of relationships (i.e. training, education and didactics) that professors adopt.

Funding Open access funding provided by Università degli Studi di Salerno within the CRUI-CARE Agreement.

\section{Declarations}

Informed Consent Informed consent was obtained from all individual participants included in the study.

Conflict of Interest The author declares no competing interests.

Open Access This article is licensed under a Creative Commons Attribution 4.0 International License, which permits use, sharing, adaptation, distribution and reproduction in any medium or format, as long as you give appropriate credit to the original author(s) and the source, provide a link to the Creative Commons licence, and indicate if changes were made. The images or other third party material in this article are included in the article's Creative Commons licence, unless indicated otherwise in a credit line to the material. If material is not included in the article's Creative Commons licence and your intended use is not permitted by statutory regulation or exceeds the permitted use, you will need to obtain permission directly from the copyright holder. To view a copy of this licence, visit http://creativecommons.org/licenses/by/4.0/. 


\section{References}

Anolli, L. (2014). La sfida della mente multiculturale. Raffella Cortina Editore.

Anolli, L. (2005). Psicologia della cultura. Il Mulino.

Bateson, Gregory. 1972. Steps to an Ecology of Mind. Chicago: University of Chicago.

Berelson, B. (1954). Content analysis. In G. Lindsey (Ed.), Handbook of social psychology: Theory \& method (Vol. 1, pp. 488-522). Addison-Wesley

Bergquist, W. H. (1992). The four cultures of the academy: Insights and strategies for improving leadership in collegiate organizations. Jossey-Bass Publishers.

Blanchet, A. (1985). L'entretien dans les sciences sociales: l'écoute, la parole et le sens. Bordas.

Bourdieu, P. (1984). Homo academicus. Editions de Minuit.

Bruner, J. S. (1990). Acts of meaning. Harvard University Press.

Bruner, J. S. (1992). Autobiography and the construction of self. Harvard University Press.

Bruner, J. S. (1994). The "remembered" self. In U. Neisser \& R. Fivush (Eds.), The remembering self: Construction and accuracy in the self-narrative. Emory symposia in cognition 6, 41-54. Cambridge University Press.

Bruner, J. S. (1996). The culture of education. Harvard University Press.

Bruner, J. S., \& Feldman (1999). La narrazione di gruppo come contesto culturale autobiografico. In Groppo M., Oragnani V., Grazzani I., Carruba L. (Eds), La psicologia culturale di Bruner. Raffaello Cortina Editore.

Bruner, J. S. (2010). Presentazione. In A. Iannaccone (Eds). Le condizioni sociali del pensiero. Unicopli.

Cole, M. (1992). Context, modularity and the cultural constitution of the development. In L.T. Weinegar e J. Valsiner (Eds.), Cildren's development within social content, vol. 2, Hillsdale, NJ, Erlbaum, pp. 5-31.

D'Andrade, R. G. (1995). The development of cognitive anthropology. Cambridge University Press.

Engeström, Y. (1990). When is a tool? Multiple meanings of artifacts in human activity. In Y. Engeström, Learning, working and imagining: Tweleve studies in activity theory. Helsinki: Orienta-Konsultit.

Gergen, K. L. (2001). Social Construction in contest. Sage.

Jodelet, D., Ohana, J., Bessi-Monino, C. \& Dannenmuller E. (1980). Systèmes de représentations du corps et groupes sociaux. CORDES.

Kleinman, A. M. (1975). Cognitive structures of traditional medical systems: Ordering, explaining and interpreting the human experience of illness. Ethnomedizin III, 1(2), 27-49.

Lancia, F. (2004). Strumenti per l'analisi dei testi. Franco Angeli.

Marsico, G. (2015). Striving for the new: Cultural psychology as a developmental science. Culture \& Psychology, 21(4), 445-454. https://doi.org/10.1177/1354067X15623020

Marsico, G., Dazzani, V., Ristum, M. \& Bastos A. C. (2015). Educational contexts and borders through a cultural lens-Looking inside. Viewing outside. Cultural Psychology of Education, 1, Geneve, Switzerland: Springer (p.359-366); In Educational contexts and borders through a cultural lens-Looking inside. Viewing outside. pp. 359-366 Geneve Springer. ISBN:978-3-319-18764-8 ISSN:2364-6780.

Marsico, G. (2018). The challenges of the schooling from cultural psychology of education. Integrative Psychological and Behavioural Sciences, 52(3), 474-489. ISSN:1932-4502. https://doi.org/10.1007/ s12124-018-9454-6

Gomes, R., Dazzani, V., \& Marsico, G. (2018). The role of "responsiveness" within the self in transitions to university. Culture \& Psychology, 24(1), 49-59. https://doi.org/10.1177/1354067X17713928

Mellone, M., Ribeiro, M., Jakobsen, A., Carotenuto, G., Romano, P., \& Pacelli, T. (2020). Mathematics professors' interpretative knowledge of students' errors and non-standard reasoning. Research in Mathematics Education, 22(2), 154-167. https://doi.org/10.1080/14794802.2019.1710557

Salvatore, S. (2005). Visioni di Università. Roma: Edizioni Carlo Amore.

Shore, B. (1996). Culture in mind: Cognition, culture, and the problem of meaning. Oxford University Press.

Iannaccone, A., Savarese, G., \& Manzi, F. (2018). Object use in children with autism: Building with blocks from a piagetian perspective. Frontiers in Education, 3(12), 1-9.

Savarese, G., Fasano, O., Mollo, M., \& Pecoraro, N. (2013). From personal identity to pluralism of intercultural identity: A study on the transferability of self-knowledge to the multicultural social contexts. Knowledge Cultures, 6, 122-126.

Savarese, G., Fasano, O., Pecoraro, N., Mollo, M., Carpinelli, \& Pierpaolo Cavallo (2019). Counseling for university students. In L. Tateo (Eds.), Educational dilemmas. A Cultural Psychology perspective (pp. 98-111). New York, London: Routledge. ISBN:9781138125605.

Skinner, D., Valsiner, J., \& Holland, D. (2001). Discerning the dialogical self: A theoretical and methodological examination of a Nepali adolescent's narrative. Forum Qualitative Sozialforschung, 2.

Valsiner, J. (2007). Culture in minds and societies. Sage. 
Valsiner, J. (1989). Human development and culture: The social nature of personality and its study. Lexington Books.

Valsiner, J. (1998). The guided mind: A sociogenetic approach. Harvard University Press.

Vygotsky, L. (1978). Mind and society: The development of higher psychological processes. Harvard University Press.

Wenger, E. (1998). Communities of practice. Learning, meaning and identity. Cambridge, NY: Cambridge University Press.

Publisher's Note Springer Nature remains neutral with regard to jurisdictional claims in published maps and institutional affiliations. 